\title{
What's on the SID Forum
}

SID Trend Monitoring Report: Urbanization in Eastern Africa Link: http://www.sidint.net/sid-trend-monitoring-report-the-greaterhorn-outlook-urbanization-in-eastern-africa/

Half of the world population now lives in the cities and 80 percent will do so by 2050. The Greater Horn of East Africa (GHEA) region is experiencing similar trends. What kind of urbanization is taking place?

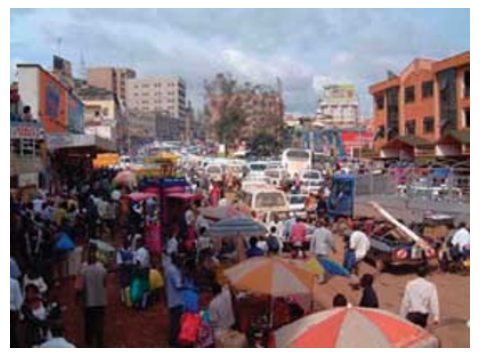

New Forms of citizen's engagement by Fatma Alloo Link: http://www.sidint.net/new-forms-of-citizen $\% \mathrm{E} 2 \% 80 \% 99$ sengagement/

It argues that only striving for property rights, nurturing an identity of nationhood, and coming out from the aid culture to a vibrant creative society, the African continent can rise.

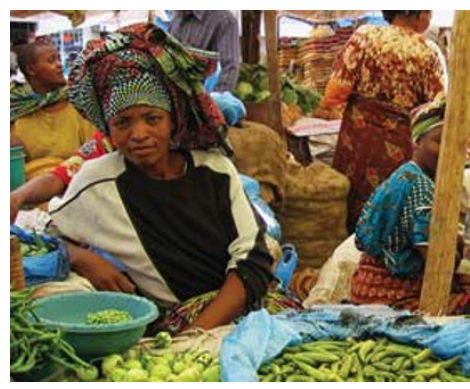

The controversy over Roma people shakes the foundation of the European Union by Ferruccio Pastore

Link: http://www.sidint.net/the-controversy-over-roma-peopleshakes-the-foundation-of-european-union/

Are poor people also entitled to full-fledged EU citizenship? The article refers to the political and institutional clash within EU over the Rome people minority.

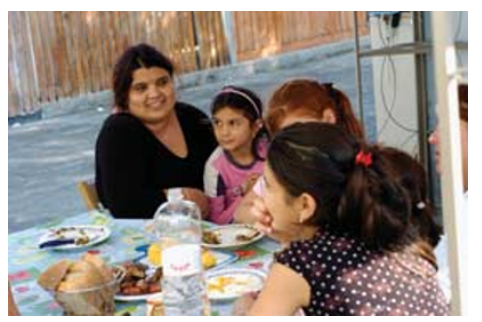

Interview with Gustavo Quilaqueo: Mapuches: A people fighting against plunder and marginalization

Link: http://www.sidint.net/interview-with-gustavo-quilaqueomapuches-a-people-fighting-against-plundering-and-marginalization/ Being displaced from their territories, the 60 percent of the Mapuche population live in urban areas, mainly in Santiago (Bolivia) but they are not recognized as political actors with collective, territorial, political rights.

\section{Gender Matters! CSW54: Making the linkages by Wendy} Harcourt

Link: http://www.sidint.net/gender-matters-csw 54-making-thelinkages/

The biggest challenge of international summits (like CSW) is to make sure that those men and women in power will at last perceive that gender is vital if we are to achieve a just and sustainable development.

Reflections from SID Buenos Aires Chapter: Communication at the heart of change by Marcelo Garcia

Link http://www.sidint.net/reflection-from-sid-buenos-aireschapter\%E2\% 80\%93-communication-at-the-heart-of-change/ It argues that communication is at heart of change, not simply as mediation, but as an arena where a community builds its destiny via politics.

Why Women's empowerment are still needed in the Palestinian Territories by Carla Pagano

Link: http://www.sidint.net/why-women\%E2\%80\%99sempowerment-programmes-are-still-needed-in-the-palestinianterritories/

It tells about the dramatic worsening of life standards of Palestinian women and girls as a result of the economic decline in the Palestinian Territories.

Policing migration in South Africa: Disinformation, Development, and Accountability by Loren Landau and Julia Hornberger

Link: http://www.sidint.net/policing-migration-in-south-africadisinformation-development-and-accountability It explains what is right and wrong behind the claim of police in Johannesburg and Pretoria that illegal immigrants are stretching police resources and manpower and make impossible to combat crime.

Children who become soldiers by Saskia Baas

Link: http://www.sidint.net/children-who-become-soldiers/ It explains that the image of a child-soldier as a helpless victim who is forced is only one part of reality and does not provide room for a better understanding of children who choose to become soldiers in an attempt to shape their destinies.

The Rosarno riots and the European debate on Immigratio: A southern point of view by Ayman Zohry

Link: http://www.sidint.net/rosarno-riots-and-the-europeandebate-on-immigration-a-southern-point-of-view/

It is clear that, despite the openness, globalization, and inter-regionalism, perverse tendencies of fear and racism are emerging more and more in Europe. What happened in Rosarno (Italy, in 2010) is just a piece in the immigration puzzle of Europe. 